\title{
Proteomic identification of galectin-11 and 14 ligands from Haemonchus contortus
}

\author{
Dhanasekaran Sakthivel ${ }^{1,2,3}$, Jaclyn Swan ${ }^{1}$, Sarah Preston ${ }^{4,5}$, MD Shakif-Azam ${ }^{3}$, Pierre Faou ${ }^{6}$, Yaqing Jiao ${ }^{4}$ \\ , Rachael Downs ${ }^{6}$, Harinda Rajapaksha ${ }^{6}$, Robin Gasser ${ }^{4}$, David Piedrafita ${ }^{\text {Corresp., }}{ }^{3}$, Travis Beddoe ${ }^{\text {Corresp. } 1}$ \\ 1 Department of Animal, Plant and Soil Science and Centre for AgriBioscience (AgriBio), La Trobe University, Bundoora, Victoria, Australia \\ 2 Department of Biochemistry and Molecular Biology, Monash University, Clayton, Australia \\ 3 School of Applied and Biomedical Sciences, Federation University, Churchill, Australia \\ 4 Melbourne Veterinary School, Faculty of Veterinary and Agricultural Sciences, University of Melbourne, Melbourne, Australia \\ 5 Faculty of Science and Technology, Federation University, Ballarat, Australia \\ 6 Department of Biochemistry \& Genetics, La Trobe Institute for Molecular Science, La Trobe University, Bundoora, Australia \\ Corresponding Authors: David Piedrafita, Travis Beddoe \\ Email address: david.piedrafita@federation.edu.au, t.beddoe@latrobe.edu.au
}

Haemonchus contortus is the most pathogenic nematode of small ruminants. Infection in sheep and goats results in anaemia that decreases animal productivity and can ultimately cause death. The involvement of ruminant-specific galectin-11 (LGALS-11) and galectin-14 (LGALS-14) has been postulated to play important roles in protective immune responses against parasitic infection; however, their ligands are unknown. In the current study, LGALS-11 and LGALS-14 ligands in H. contortus were identified from larval (L4) and adult parasitic stages extracts using immobilised LGALS-11 and LGALS-14 affinity column chromatography and mass spectrometry. Both LGALS-11 and LGALS-14 bound more putative protein targets in the adult stage of $\mathrm{H}$. contortus (43 proteins) when compared to the larval stage ( 2 proteins). Of the 43 proteins identified in the adult stage, 34 and 35 proteins were bound by LGALS-11 and LGALS-14, respectively, with 26 proteins binding to both galectins. Interestingly, hematophagous stage-specific sperm-coating protein and zinc metalloprotease (M13), which are known vaccine candidates, were identified as putative ligands of both LGALS-11 and LGALS-14. The identification of glycoproteins of $H$. contortus by LGALS-11 and LGALS-14 provide new insights into host-parasite interactions and the potential for developing new interventions. 


\section{Proteomic identification of galectin-11 and 14 ligands from}

\section{Haemonchus contortus}

3

4
Dhanasekaran Sakthivel ${ }^{1,2,3}$, Jaclyn Swan ${ }^{3}$, Sarah Preston ${ }^{4,6}$, MD Shakif-Azam ${ }^{2}$, Pierre Faou ${ }^{5}$, Yaqing $\mathrm{Jiao}^{4}$, Rachael Downs ${ }^{5}$, Harinda Rajapaksha ${ }^{5}$, Robin B Gasser ${ }^{4}$, David Piedrafita ${ }^{2 *}$ and Travis Beddoe $3^{*}$

${ }^{1}$ Department of Biochemistry and Molecular Biology, Monash University, Clayton, Victoria 3800, Australia.

${ }^{2}$ School of Applied and Biomedical Sciences, Federation University, Churchill, Victoria 3842, Australia.

${ }^{3}$ Department of Animal, Plant and Soil Science and Centre for AgriBioscience (AgriBio), La Trobe University, Victoria 3086, Australia.

${ }^{4}$ Melbourne Veterinary School, Faculty of Veterinary and Agricultural Sciences, The University of Melbourne, Victoria, 3010, Australia.

${ }^{5}$ Department of Biochemistry \& Genetics, La Trobe Institute for Molecular Science La Trobe University, Victoria 3086, Australia.

${ }^{6}$ Faculty of Science and Technology, Federation University, Ballarat, VIC, 3350, Australia.

*Corresponding authors

Travis Beddoe; email: t.beddoe@latrobe.edu.au

David Piedrafita; email:david.piedrafita@federation.edu.au

(1) 


\section{Abstract}

40 Haemonchus contortus is the most pathogenic nematode of small ruminants. Infection in sheep

41 and goats results in anaemia that decreases animal productivity and can ultimately cause death.

42 The involvement of ruminant-specific galectin-11 (LGALS-11) and galectin-14 (LGALS-14) has

43 been postulated to play important roles in protective immune responses against parasitic

44 infection; however, their ligands are unknown. In the current study, LGALS-11 and LGALS-14

45 ligands in $H$. contortus were identified from larval (L4) and adult parasitic stages extracts using

46 immobilised LGALS-11 and LGALS-14 affinity column chromatography and mass

47 spectrometry. Both LGALS-11 and LGALS-14 bound more putative protein targets in the adult

48 stage of $H$. contortus (43 proteins) when compared to the larval stage (2 proteins). Of the 43

49 proteins identified in the adult stage, 34 and 35 proteins were bound by LGALS-11 and LGALS-

5014 , respectively, with 26 proteins binding to both galectins. Interestingly, hematophagous stage-

51 specific sperm-coating protein and zinc metalloprotease (M13), which are known vaccine

52 candidates, were identified as putative ligands of both LGALS-11 and LGALS-14. The

53 identification of glycoproteins of $H$. contortus by LGALS-11 and LGALS-14 provide new

54 insights into host-parasite interactions and the potential for developing new interventions. 


\section{Introduction}

65

66

67

68

69

70

Haemonchus contortus is a dominant blood feeding gastrointestinal nematode (GIN) parasite of small ruminants. Blood feeding by $H$. contortus results in haemorrhagic gastritis, oedema, diarrhoea and death in severe infections, leading to significant economic impact through decreased livestock production (Mavrot et al. 2015; McLeod 1995; Roeber et al. 2013). Sheep can develop effective immunity to $H$. contortus infection and vaccine-induced protection using H. contortus-derived molecules such as the H-gal-GP, a gut-derived, galactose-containing glycoprotein complex and integral membrane glycoprotein complex, termed H11, a family of microsomal aminopeptidases have been demonstrated, suggesting that the control of this parasite through vaccination is possible (Nisbet et al. 2016). However what host molecules recognise these glycoproteins are poorly understood. Recently it has been shown that galectins have been showed to play major roles in host defence against microbial pathogens. Galectins are a family of carbohydrate-binding molecules with characteristic domain organization and affinity for $\beta$ galactosides that mediates a variety of important cellular functions, including inflammation and immune responses due to binding both self and non-self glycans (Vasta et al. 2017).

In particular, ruminants highly upregulate the expression of two specific galectins (LGALS-11 and LGALS-14) upon infection by various parasites such as Ostertagia ostertagi, Cooperia oncophora and H. contortus (Dunphy et al. 2000; Dunphy et al. 2002; Hoorens et al. 2011; Meeusen et al. 2005). LGALS-14 is secreted by eosinophil immune cells that are critical for immunity through killing the larval stages of $H$. contortus (Balic et al. 2006; Dunphy et al. 2002; Young et al. 2009). LGALS-14 is thought to be the homologue of human galectin-10, which is also secreted by eosinophils (Ackerman et al. 2002). Analysis of $H$. contortus infected sheep demonstrated release of LGALS-14 into the gastrointestinal mucus, the interface of host and parasite interaction (Dunphy et al. 2002). In addition, kinetic studies of LGAL-14 showed that release into the mucus occurred soon after challenge infection, and correlated with a reduction in 
89 parasitic burden (Robinson et al. 2011). Additional it has been shown that LGAL-14 can bind

90 directly to another parasite Fasciola hepatica suggesting it can inhibit infection (Young et al.

91 2012).

92 The second galectin (LGALS-11) is specifically expressed and secreted during H. contortus

93 infections in previously infected sheep that had developed resistance to the parasite (Dunphy et

94 al. 2000). Immunohistochemistry revealed that LGALS-11 was secreted by epithelial cells lining

95 the gastrointestinal tract, where it was localised to the nucleus and cytoplasm of cells. Analysis

96 of the mucosal contents lining the gastrointestinal tract also revealed secretion of LGALS-11 into

97 the mucus. An observation of increased mucus stickiness corresponding with the production of

98 LGALS-11 suggested that it might work by interacting with the mucus to impede $H$. contortus

99 motility (Robinson et al. 2011). Recent immunofluorescent staining techniques using a

100 recombinant form of galectin-11 have revealed binding to the fourth larval stage and adult $H$.

101 contortus that has resulted in impaired development. These studies suggest a more direct or

102 additional role for LGALS-11 during $H$. contortus infections.

103 It appears that both LGALS-11 and LGALS-14 mediate critical immune regulatory effects

104 and/or mediate direct parasite stage-specific killing (Haslam et al. 1998; Preston et al. 2015b).

105 Although the interactions of these host galectin-parasite glycoconjugates are likely to be critical

106 for parasite control, the parasite glycoconjugate molecules that they recognise are unknown. For

107 the first time, this study describes the ligands of sheep LGALS-11 and LGALS-14 in larval and

108 adult stages of $H$. contortus.

109

\section{Materials and Methods}

\section{Preparation of $\mathbf{L} 4$ larvae and collection of adult parasites}

112 H. contortus (Haecon-5 strain) was maintained in Professor Gasser's laboratory, Melbourne

113 Veterinary School, The University of Melbourne and was used in this study. Mature fourth stage

114 larvae (L4 stage) and adults of $H$. contortus were prepared using established protocols (Preston

115 et al. 2015a). Briefly, third-stage larvae (L3) were isolated from faeces from H. contortus-

116 infected sheep. The cuticle was removed from the L3s by using sodium hypochlorite, the

117 exsheathed L3 (xL3) worms were washed three times with $0.9 \%(\mathrm{w} / \mathrm{v})$ normal saline. 
118 Approximately 2000 xL3 / ml worms were resuspended in Dulbecco's modified Eagle

119 Medium+GlutaMax (DMEM) (Gibco-Invitrogen, USA) containing 10,000 IU/ml of penicillin

120 and 10,000 $\mu \mathrm{g} / \mathrm{ml}$ of streptomycin (Gibco-Invitrogen, USA) and $0.5 \%$ (v/v) amphotericin (GE

121 Healthcare, UK). Medium containing xL3s was incubated at $37{ }^{\circ} \mathrm{C}$ with $10 \%(\mathrm{v} / \mathrm{v}) \mathrm{CO}_{2}$ for 7

122 days. Fresh DMEM was substituted at two-day intervals and larval development was examined

123 each day. The xL3 and L4 stages were differentiated based on distinctive morphological

124 characteristics (see Preston et al., 2015a). Animal experimental procedures were approved by the

125 Monash University Animal Ethics Committee (Ethics \# SOBSA/P/2009/44). Adults of $H$.

126 contortus were collected from Merino ewes (8-12 months old) which were experimentally

127 infected with 10,000 L3s and the infected animals were euthanised 52 days post infection by

128 injection of pentobarbitone (Lethobarb ${ }^{\circledR}$, Virbac Pty Ltd, Australia). Approximately 5,000 adult

129 worms of mixed sex were collected from the abomasal content and washed five times with $0.9 \%$

130 (v/v) biological saline (Baxter, Australia). Immediately after washing, the worms were snap

131 frozen in liquid nitrogen and stored at $-80^{\circ} \mathrm{C}$ until further use.

132 Total larval protein lysate preparation

133 Lysates were prepared using radioimmunoprecipitation assay buffer (RIPA) as previously

134 described with minor modifications (Maduzia et al. 2011). Briefly, $500 \mathrm{mg}$ of larval or adult $H$.

135 contortus were incubated with $100 \mathrm{mM} \beta$-D-galactose containing $0.9 \%(\mathrm{v} / \mathrm{v})$ normal saline for

$13612 \mathrm{~h}$ to remove native galectins (bound to the adult parasite surface recovered from infected

137 sheep) and washed three times with normal saline. Larval or adult $H$. contortus were then

138 resuspended in $5 \mathrm{ml}$ of ice-cold RIPA buffer [20 mM Tris-HCL pH 7.2, $100 \mathrm{mM} \mathrm{NaCl,} \mathrm{1 \%} \mathrm{(v/v)}$

139 Nonidet P-40, $0.1 \%$ (w/v) sodium deoxycholate (DOC), $0.05 \%$ (w/v) sodium dodecyl sulphate

140 (SDS), $1 \%$ (v/v) Triton X-100, $10 \mathrm{mM} \mathrm{TCEP} \mathrm{(Tris} \mathrm{(2-carboxyethyl)} \mathrm{phosphine)]} \mathrm{and} \mathrm{lysed} \mathrm{by}$

141 sonication (30 sec, 8 times with three min interval at $40 \%$ amplitude). Cellular debris was

142 removed by centrifugation $(15000 \times \mathrm{g}$ for $20 \mathrm{~min})$ at $4{ }^{\circ} \mathrm{C}$, and any particles in the supernatant

143 removed by filtering through a $0.22 \mu \mathrm{m}$ filter. Lysates were dialysed using $3 \mathrm{kDa}$ molecular

144 weight cut-off against binding buffer [(20 mM Tris- $\mathrm{HCl} \mathrm{pH} 7.5,100 \mathrm{mM} \mathrm{NaCl}, 0.5 \%$ (v/v)

145 Nonidet P-40, $0.1 \%(\mathrm{w} / \mathrm{v})$ DOC, $0.05 \%$ (w/v) SDS, 1\% (v/v) Triton X-100, $10 \mathrm{mM} \mathrm{TCEP)].}$

146

147 SDS-PAGE

148 LGALS-11 and LGALS-14 affinity column 
149 Recombinant LGALS-11 and LGALS-14 were expressed and purified as described previously

150 ((Sakthivel et al. 2015); Fig. 1). The recombinant protein $(5 \mathrm{mg} / \mathrm{ml})$ was buffer-exchanged into

151 HEPES buffer (10 mM HEPES-NaOH pH 7.5, $100 \mathrm{mM} \mathrm{NaCl}, 10 \mathrm{mM}$ TCEP) and immobilised

152 by coupling to N-hydroxysuccinamide (NHS)-activated Sepharose (GE Healthcare, UK)

153 following the manufacturer's protocol. Briefly, $4 \mathrm{ml}$ of NHS-activated Sepharose was washed

154 with 15 column-volumes of ice-cold $1 \mathrm{mM} \mathrm{HCl}$. The washed Sepharose beads were equilibrated

155 with $20 \mathrm{ml}$ of coupling buffer (10 mM HEPES-NaOH pH 7.5, $100 \mathrm{mM} \mathrm{NaCl}, 10 \mathrm{mM}$ TCEP).

156 Following equilibration, LGALS-11 and LGALS-14 were added separately to the activated

157 Sepharose and allowed to couple for $5 \mathrm{~h}$ at $22{ }^{\circ} \mathrm{C}$. Following the coupling reaction, the unused,

158 activated sites were blocked using 15 column-volumes of blocking buffer (100 mM Tris-HCl pH

$1598.0,100 \mathrm{mM} \mathrm{NaCl}$ ) for $3 \mathrm{~h}$. Following blocking, the Sepharose beads were washed alternatively

160 six times with 15 column-volumes of $100 \mathrm{mM}$ Tris-HCL pH 8.0 followed by $100 \mathrm{mM}$ sodium

161 acetate $\mathrm{pH} 5.0$ and then $250 \mathrm{mM} \mathrm{NaCl}$. The galectin affinity column was maintained in storage

162 buffer (20 mM Tris-HCl pH 8.0, 100 mM NaCl, 10 mM TCEP, NaAc $0.02 \%$ (w/v)) until further

163 use. A control resin was also prepared without any protein ligand.

164

\section{Isolation of LGALS-11 and LGALS-14 parasite ligands}

166 Immobilised LGALS-11, -14 or control slurry (1 ml) was loaded into individual columns. Larval

167 and adult $H$. contortus lysates $(150 \mathrm{mg})$ were diluted with $5 \mathrm{ml}$ of binding buffer $(20 \mathrm{mM}$ Tris-

$168 \mathrm{HCl} \mathrm{pH} 7.5,100 \mathrm{mM} \mathrm{NaCl}, 0.5 \%$ (v/v) Nonidet P-40, $0.1 \%$ (w/v) DOC, $0.05 \%$ (w/v) SDS, $1 \%$

$169(\mathrm{v} / \mathrm{v})$ Triton X-100, $10 \mathrm{mM}$ TCEP) and applied to the galectin affinity column and incubated for

$17016 \mathrm{~h}$ at $4^{\circ} \mathrm{C}$. Thereafter, columns were washed three times with $15 \mathrm{ml}$ of RIPA buffer, the

171 captured protein fractions were eluted by incubating for $2 \mathrm{~h}$ with galactose elution buffer (250

$172 \mathrm{mM} \beta$-D-galactose $20 \mathrm{mM}$ Tris- $\mathrm{HCl} \mathrm{pH}$ 8.0, $100 \mathrm{mM} \mathrm{NaCl}, 10 \mathrm{mM}$ TCEP) and the resultant

173 supernatant was subjected to LC-MS/MS analysis to identify the protein molecules present. The

174 eluted protein products were analysed by $12 \%$ SDS-PAGE stained with nitrate. The unbound

175 fractions, column wash and eluted proteins fractions were concentrated using sodium

176 deoxycholate/trichloroacetic acid precipitation method to allow the visualisation of protein

177 products as previously described (Arnold \& Ulbrich-Hofmann 1999).

178 
179 Mass spectrometry (ESI-LC-MS/MS) analysis of galectin binding proteins

180 Eluted protein samples were dissolved in digestion buffer ( $8 \mathrm{M}$ urea, $50 \mathrm{mM} \mathrm{NH}_{4} \mathrm{HCO}_{3}, 10 \mathrm{mM}$

181 dithiothreitol) and incubated at $25^{\circ} \mathrm{C}$ for $5 \mathrm{~h}$. Following incubation, iodoacetamide (IAA) was

182 added to final concentration of $55 \mathrm{mM}$ to alkylate thiol groups and incubated for $35 \mathrm{~min}$ at $20{ }^{\circ} \mathrm{C}$

183 in the dark. The alkylated protein preparation was diluted with $1 \mathrm{M}$ urea in $25 \mathrm{mM}$ ammonium

184 bicarbonate ( $\mathrm{pH} \mathrm{8.5)}$ ) and sequencing-grade trypsin (Promega) was added to a final concentration

185 of $5 \mu \mathrm{M}$. The reaction was incubated for $16 \mathrm{~h}$ at $37^{\circ} \mathrm{C}$ in the dark. The digests were acidified

186 with $1 \%(\mathrm{v} / \mathrm{v})$ trifluoroacetic acid (TFA) and the peptides desalted on poly(styrene-

187 divinylbebzebe) copolymer (SDB) (Empore) StageTips as described previously (Rappsilber et al. 188 2007).

189 Trypsin-digested peptides were reconstituted in $0.1 \%(\mathrm{v} / \mathrm{v})$ TFA and $2 \%(\mathrm{v} / \mathrm{v})$ acetonitrile (ACN)

190 and then loaded onto a guard column $\left(\mathrm{C}_{18}\right.$ PepMap $100 \mu \mathrm{m}$ ID $\times 2 \mathrm{~cm}$ trapping column, Thermo-

191 Fisher Scientific) at $5 \mu \mathrm{l} / \mathrm{min}$ and washed for $6 \mathrm{~min}$ before switching the guard column, in line

192 with the analytical column (Vydac MS C $18,3 \mu \mathrm{m}, 300 \AA$ and $75 \mu \mathrm{m} \mathrm{ID} \times 25 \mathrm{~cm}$ ). The separation

193 of peptides was performed at $300 \mathrm{nl} / \mathrm{min}$ using a non-linear ACN gradient of buffer A $(0.1 \%$

194 (v/v) formic acid, $2 \%(\mathrm{v} / \mathrm{v}) \mathrm{ACN})$ and buffer B (0.1\% (v/v) formic acid, $80 \%(\mathrm{v} / \mathrm{v}) \mathrm{ACN})$,

195 starting at 5\% (v/v) buffer B to 55\% for $120 \mathrm{~min}$. Data were collected on an Orbitrap Elite

196 (Thermo-Fisher Scientific) in a data-dependent acquisition mode using m/z 300-1500 as MS

197 scan range, CID MS/MS spectra and were collected for the 20 most intense ions. Dynamic

198 exclusion parameters were set as described previously (Nguyen et al. 2016). The Orbitrap Elite

199 was operated in dual analyser mode, with the Orbitrap analyser being used for MS and the linear

200 trap being used for MS/MS. Pull-down and LC-MS/MS analysis were performed three times on

201 different days.

202

203 Database search and protein identification

204 The MS/MS spectra obtained from the Orbitrap analyser was used to interrogate the Swiss-Prot

205 Haemonchus contortus FASTA database (downloaded on 07.31.2016, 21,201 protein entries) in

206 conjugation with common contaminants by use of the Mascot search engine (Matrix Science

207 Ltd., London, UK) as described previously (Perkins et al. 1999). Briefly, carbamidomethylation 
208 of cysteines was set as a fixed modification, acetylation of protein N-termini, methionine

209 oxidation were included as variable modifications. Precursor mass tolerance was $10 \mathrm{ppm}$,

210 product ions were searched at 0.5 Da tolerances, minimum peptide length defined at 6 , maximum

211 peptide length 144, and peptide spectral matches (PSM) were validated using Percolator based

212 on q-values at a $1 \%$ false discovery rate (FDR). Both peptide and protein identifications were

213 reported at a false discovery rate (FDR) of $1 \%$. The mass spectrometry proteomics data have

214 been deposited to the ProteomeXchange Consortium via the PRIDE partner repository with the

215 data set identifier PXD008435 and 10.6019/PXD008435.

\section{Protein-protein interaction analysis and visualisation}

217 Normalized spectral abundance factor (NSAF) values were calculated for the identified proteins

218 using the Scaffold software v4.7.2 (Searle 2010). Then proteins were subjected to the

219 significance analysis of interactome (SAINT) (Choi et al. 2011) to identify bona fide protein-

220 protein interactions after removing all zero or missing rows. Proteins with a SAINT probability

221 greater than 0.9 were selected as high probability interactions. Finally, the resulting interaction

222 network was visualised using the Cytoscape v3.4.0 (Shannon et al. 2003).

223

224

225

226

227

228

\section{Analysis of glycosylation}

The $\mathrm{N}$ - and O-linked glycosylation pattern and the signal peptides of eluted proteins were analysed following the instructions provided in the glycosylation analysis server. Briefly, Nglycosylation and signal peptide was analysed using NetNGlyc 1.0 server

229 (http://www.cbs.dtu.dk/services/NetNGlyc/). Whereas the O-glycosylation pattern was analysed 230 using NetOGlyc 4.0 Server (http://www.cbs.dtu.dk/services/NetOGlyc/). The results obtained

231 from the $\mathrm{N}$ and $\mathrm{O}$ glycosylation servers were provided as supplementary results.

232

233

234

235

Identification of proteins from $\boldsymbol{H}$. contortus that interact with LGALS-11 and LGALS-14

236 Affinity purification and identification of $H$. contortus proteins interacting with LGALS-11 and LGALS-14 is summarized in Fig. S1. Lysates of L4 and adult stages were assessed before loading onto the columns containing the Sepharose immobilised LGALS-11 and LGALS-14 and are shown in Fig. 1a. Multiple bands were observed, with both larval and adult lysates containing 
240 a broad range of proteins of differing molecular weights. Following the application of L4 and

241 adult lysates to affinity columns, containing immobilised galectins, bound parasite molecules

242 were eluted with elution buffer-containing galactose (Fig. 1b \& 1c). The eluted molecules from

243 both affinity columns and a control column were subjected to LC-MS/MS. Proteins that were

244 identified in 2 of the 3 biological replicates were included for further analysis and the proteins

245 that were bound to control resin (Table S1) were removed from the analysis. Overall, 43

246 individual proteins were identified and grouped based on their respective known or putative

247 biological function(s) (Table 1). The greatest number of proteins identified was in the adult stage

248 of $H$. contortus; with 34 proteins binding to LGALS-11 and 35 proteins binding to LGALS-14.

249 Of those identified proteins, 26 proteins were found to bind to both LGALS-11 and LGALS-14

250 (Fig. 2). In the L4 larval stage, LGALS-11 and LGALS-14 could bind to 0 and 2 proteins

251 respectively.

252

253 Composition of LGALS-11 and LGALS-14 ligands

254 Approximately $69 \%$ of proteins in $H$. contortus that bound specifically to LGALS-11 and/or

255 LGALS-14 were inferred to be involved in metabolic and regulatory processes (Table 1, Fig. 3 ).

256 Most of these proteins ( $70 \%$ ) were likely involved in metabolic activities, such as energy

257 metabolism, transcription and translation. These proteins predominantly included regulatory

258 enzymes, such as peptidases, carboxyl transferases, aldo-keto reductases, deoxynucleoside

259 kinase, dehydrogenase, amidinotransferase and RNA polymerase. Another protein group ( $\sim 9 \%)$

260 identified represented structural proteins, such as actin, myosin and collagen from $H$. contortus

261 (Table 1, Fig. 3). Other proteins identified had putative roles in molecular transport (e.g., lipid

262 and amino acid transport) or had no assigned function(s) (Fig. 3). In silico analysis revealed that

263 approximately $65 \%$ of the proteins of the adult stage, that bound specifically to LGALS-11 and

264 LGALS-14 had one or more potential glycosylation site (Table 2). On the contrary, about $35 \%$

265 of adult stages specific proteins that bound to LGALS-11 and LGALS-14 were predicted as non-

266 glycosylated. Though animal lectins have a primary preference for glycoconjugates, it is believed

267 that the LGALS-11 and LGALS-14 might also display a glycan independent protein-protein

268 interaction activity similar to previously reported for galectin-1 and galectin-3 (Bawumia et al.

269 2003; Camby et al. 2006; Menon et al. 2000; Paz 2001). Galectin-3 has also been shown to

270 interact with proteoglycans which are proteins which have covalently attached 
271 glycosaminoglycan chain (Talaga et al. 2016). Most mammalian proteoglycans are major

272 component of extracellular matrix such collagen. A nematode cuticle collagen and collagen triple

273 helix repeat protein (W6NAH7) was identified in adult stages by LGALS-11 and LGALS-14

274 suggesting that LGALS-11 and LGALS-14 can interact with proteoglycans.

275

276 Larval and adult ligands of LGALS-11 and LGALS-14

277 More putative ligands $(\mathrm{n}=43)$ were identified in the adult stage of $H$. contortus compared with

278 larval stages $(\mathrm{n}=2)$ following galectin pull-down assays. Although the L4 stage is a histotropic

279 stage (in glands of the stomach) and would be expected to be in intimate contact with

280 inflammatory mediators, including galectins, it moults (with a change in antigenic profile) within

281 48-72 $\mathrm{h}$ into the immature adult (Meeusen et al. 2005). This would be expected to limit the

282 antigenic exposure of these parasite antigens to the host. Compared to the adult stage that is

283 relatively long-lived (6-8 weeks), allowing a sustained interaction of host molecules with

284 parasite antigens (Nikolaou \& Gasser 2006; Veglia 1915). This interaction might be reflected in

285 the specific and localised binding of LGALS-11 in the larvae and the significant staining of

286 LGALS-11 on the surface of adult $H$. contortus (see Preston et al., 2015b). In addition, the L4

287 stage is relatively small ( $750-850 \mu \mathrm{m}$ long), whereas the adult stage is usually $10-30 \mathrm{~mm}$ long.

288

289 A protein-protein interaction network was drawn for LGALS-11 and LGALS-14 affinity purified

290 proteins specific to adult parasitic stage revealed that, LGALS-11 and LGALS-14 found to

291 interact 5 unique proteins individually. Whereas 9 proteins were found to interact with both

292 LGALS-11 and LGALS-14 (Fig. 4). Carboxyl transferase, aldo keto reductase and myosin

293 displayed unique interaction with LGALS-11. Whereas zinc metallopeptidase M13, porin

294 domain containing protein, von Willebrand factor-like domain containing protein and

295 mitochondrial solution substrate carrier protein displayed an interaction network unique to

296 LGALS-14. Peptidase S28, alpha beta hydrolase fold-1, glutamate phenylalanine leucine valine

297 dehydrogenase, nematode cuticle collagen, lipid transport protein containing vitellinogen and

298 von Willebrand factor-like domains were found to interact both LGALS-11 and LGALS-14

299 (Fig.4).

300 Protease and phosphatase ligands 
301 A significant number of proteins $(\mathrm{n}=19)$ with enzyme activity were identified in adults, and

302 similar proteins have been described in other 'omic' studies, suggesting that many of these

303 enzymes of the protease family are conserved and evolutionarily related in nematodes (Campbell

304 et al. 2011; Ghedin et al. 2007; Schwarz et al. 2013). A notable protease identified in the adult

305 stage, is zinc metallopeptidase (M13 protease or neprilysin). Zinc metallopeptidases have been

306 reported as the major protein fraction of host protective glycoprotein complex H-gal-GP

307 (Haemonchus galactose containing glycoprotein). Another important metalloprotease is H11

308 family which has been shown to provide protection when used as vaccine antigen (Newton \&

309 Munn 1999). Several studies isolated zinc metallopeptidases from crude extracts of H. contortus

310 using lectins that have a binding preference to $\beta$-D-galactose and, following vaccination of

311 sheep, led to reduced worm burdens following challenge infection (Dicker et al. 2014; Newlands

312 GFJ 2006; Smith et al. 1999; Smith et al. 2000). It appears inhibition of metalloproteases

313 interferes with ability of $H$. contortus to digest its blood meal.

314

315 Another important group of proteases were found to interact with LGALS-11 and LGALS-14,

316 which are S28 family (Table 1). Four different S28 proteases interacted were shown to interact

317 with LGALS-11 and LGALS-14 in particular HCOI_01497800, HCOI_01562400 and

318 HCOI_01624000 which have homology to contortin (Fig. S2). Contortin is intestinal antigen of

$319 H$. contortus which induced significant levels of protection when used to vaccinate lambs (Munn

320 et al. 1987). Contortin is comprised of two proteins, Hc-PCP1 and Hc-PCP2 that can degraded

321 the C-terminal end of the fibrinogen alpha-chain therefore inhibiting blood clotting (Geldhof \&

322 Knox 2008).

323

324 Blood ligands

325 A number of parasite molecules were identified that interact with host galectins and are

326 potentially involved in manipulating the host blood function in the adult stage but not larvae of

327 H. contortus. That the adult stage of this nematode is primary a blood feeder may explain the

328 lack of such molecules identified in the larvae. Blood feeding parasites are known to use several

329 mechanisms to suppress platelet aggregation, allowing prolonged blood feeding by retarding

330 blood clotting (Liu \& Weller 1992). The von-Willebrand factor (VWF) is a well-known protein 
331 reported in integrin and other extracellular proteins (Whittaker \& Hynes 2002). The binding of a

332 C-type lectin (CLEC4M), with VWF has previously been shown to enhance the internalisation of

333 VWF by the host cells and alter plasma levels of VWF (Rydz et al. 2013). In previous reports,

334 proteins containing the VWF-like domain are localised in nematode intestine and suggested to

335 play critical roles in cell adhesion and platelet aggregation (Wohner et al. 2012). A multimeric

336 glycoprotein containing VWF-like domain was identified previously in adult $H$. contortus that

337 can suppress platelet aggregation (Crab et al. 2002). In this study, a protein containing a VWF-

338 like domain (W6ND82) was eluted from the LGAL14 column, which might suggest that this

339 host galectin plays a role in potential modulating the ability of the parasite to suppress blood

340 clotting. This protein was not detected in larval stage by both LGALS-11 and LGALS-14.

341 However, the functional significance of VWF domain containing proteins in parasitised animals

342 remains unknown, warranting further study.

\section{Specific sperm-coating protein (SCP)}

345 The stage-specific sperm-coating protein (SCP) identified interacting with host galectins in this

346 study are common to many nematode species (Cantacessi \& Gasser 2012) and are suggested to

347 play critical roles in infection and immunomodulatory events such as neutrophil inhibition

348 (Cantacessi et al. 2012; Gadahi et al. 2016; Hewitson et al. 2009). Transcriptomic studies of $H$.

349 contortus have identified that 54 genes containing one or more SCP-like domains are

350 upregulated in the blood-feeding adult, suggesting that SCP proteins have active and stage-

351 specific involvement at the onset of blood feeding (Wang \& Kim 2003). Similar SCP domain

352 containing proteins (Hc24 and Hc40) were reported in excretory/secretory proteins of $H$.

353 contortus (Yatsuda et al. 2003). Although there is some information for SCP domain-containing

354 proteins in C. elegans (O'Rourke et al. 2006; Wang \& Kim 2003), their biological functions in

355 H. contortus needs experimental investigation.

356

357 Conclusion

358 Recently, host galectins have been hypothesised to interact with molecules to modulate hostpathogen interactions in ruminants (Hoorens et al. 2011; Kemp et al. 2009; Preston et al. 2015b). 
360 The finding that LGAL-14 is concentrated within eosinophils (an immune cell considered a

361 major mediator of parasite killing, including of $H$. contortus) suggested the possibility of a direct

362 role for ruminant galectins in mediating parasite-killing (Meeusen \& Balic 2000; Robinson et al.

363 2011). The subsequent demonstration of direct binding of LGAL-11 to H. contortus and their

364 ability to inhibit larval development and growth in vitro has confirmed the roles of galectins and

365 ability to directly kill relatively large multicellular pathogens (Preston et al. 2015b).

366 The parasite surface is the key contact with the host and is often considered important source of

367 potential vaccine molecules. Correspondingly, $45 \%$ of the glycoproteins that the two galectins

368 bound were membrane proteins of the adult stage of $H$. contortus, and included vitelline, myosin

369 and M13 protein (neprilysin); these proteins have been previously assessed as vaccine candidates

370 (Knox 2011; Strube et al. 2015; Tellam et al. 2002). This evidence would indicate that other

371 putative glycoproteins identified here by these ruminant galectins might facilitate the

372 identification of new intervention targets and, thus, warrant further investigation. In conclusion,

373 the analysis of parasite proteins recognised by galectins that are involved in resistance to

374 parasites (Guo et al. 2016; Preston et al. 2015a; Preston et al. 2015b), has identified several

375 interesting stage-specific proteins. Exploring the possible biological roles and potential

376 antihelminthic activities of these proteins has significant potential to advance our understanding

377 of the host-parasite interplay and inform future parasite control strategies.

378

379 Acknowledgements

380

381 DS also thanks Jyostna Nagpal for supporting DS in making high quality images. DS and DP

382 thank Fiona Tegart for supporting in animal maintenance during the experiment. 
384 References

385 Ackerman SJ, Liu L, Kwatia MA, Savage MP, Leonidas DD, Swaminathan GJ, and Acharya KR.

386

387

388

389

390

391

392

393

394

395

396

397

398

400

401

402

403

404

405

406

407 2002. Charcot-Leyden Crystal Protein (Galectin-10) Is Not a Dual Function Galectin with Lysophospholipase Activity but Binds a Lysophospholipase Inhibitor in a Novel Structural Fashion. Journal of Biological Chemistry 277:14859-14868.

Arnold U, and Ulbrich-Hofmann R. 1999. Quantitative Protein Precipitation from Guanidine Hydrochloride-Containing Solutions by Sodium Deoxycholate/Trichloroacetic Acid. Analytical Biochemistry 271:197-199. https://doi.org/10.1006/abio.1999.4149

Balic A, Cunningham CP, and Meeusen ENT. 2006. Eosinophil interactions with Haemonchus contortus larvae in the ovine gastrointestinal tract. Parasite Immunology 28:107-115. 10.1111/j.1365-3024.2006.00816.x

Bawumia S, Barboni Eminia AM, Menon Rajesh P, and Colin Hughes R. 2003. Specificity of interactions of galectin-3 with Chrp, a cysteine- and histidine-rich cytoplasmic protein. Biochimie 85:189-194. https://doi.org/10.1016/S0300-9084(03)00007-5

Camby I, Le Mercier M, Lefranc F, and Kiss R. 2006. Galectin-1: a small protein with major functions. Glycobiology 16:137R-157R. 10.1093/glycob/cwl025

Campbell BE, Hofmann A, McCluskey A, and Gasser RB. 2011. Serine/threonine phosphatases in socioeconomically important parasitic nematodes-Prospects as novel drug targets? Biotechnology Advances 29:28-39. http://dx.doi.org/10.1016/j.biotechadv.2010.08.008

Cantacessi C, and Gasser RB. 2012. SCP/TAPS proteins in helminths - Where to from now? Molecular and Cellular Probes 26:54-59. https://doi.org/10.1016/j.mcp.2011.10.001

Cantacessi C, Hofmann A, Young ND, Broder U, Hall RS, Loukas A, and Gasser RB. 2012. Insights into SCP/TAPS proteins of liver flukes based on large-scale bioinformatic analyses of sequence datasets. PLOS ONE 7:e31164. 10.1371/journal.pone.0031164 
408 Choi H, Larsen B, Lin Z-Y, Breitkreutz A, Mellacheruvu D, Fermin D, Qin ZS, Tyers M,

409

410

411

412

413

414

415

416

417

418

419

420

421

422

423

424

425

426

427

428

429

430

431

432

433

434 Gingras A-C, and Nesvizhskii AI. 2011. SAINT: Probabilistic Scoring of Affinity Purification - Mass Spectrometry Data. Nature methods 8:70-73. 10.1038/nmeth.1541

Crab A, Noppe W, Pelicaen C, Hoorelbeke KV, and Deckmyn H. 2002. The parasitic hematophagous worm Haemonchus contortus inhibits human platelet aggregation and adhesion: partial purification of a platelet inhibitor. Thrombosis and Haemostasis 87:899904.

Dicker AJ, Inglis NF, Manson EDT, Subhadra S, Illangopathy M, Muthusamy R, and Knox DP. 2014. Proteomic analysis of Mecistocirrus digitatus and Haemonchus contortus intestinal protein extracts and subsequent efficacy testing in a vaccine trial. PLOS Neglected Tropical Diseases 8:e2909. 10.1371/journal.pntd.0002909

Dunphy JL, Balic A, Barcham GJ, Horvath AJ, Nash AD, and Meeusen ENT. 2000. Isolation and characterization of a novel inducible mammalian galectin. Journal of Biological Chemistry 275:32106-32113. 10.1074/jbc.M003739200

Dunphy JL, Barcham GJ, Bischof RJ, Young AR, Nash A, and Meeusen ENT. 2002. Isolation and characterization of a novel eosinophil-specific galectin released into the lungs in response to allergen challenge. Journal of Biological Chemistry 277:14916-14924.

Gadahi JA, Wang S, Bo G, Ehsan M, Yan R, Song X, Xu L, and Li X. 2016. Proteomic analysis of the excretory and secretory proteins of Haemonchus contortus (HcESP) binding to goat PBMCs in vivo revealed stage-specific binding profiles. PLOS ONE 11:e0159796. 10.1371/journal.pone.0159796

Geldhof P, and Knox D. 2008. The intestinal contortin structure in Haemonchus contortus: an immobilised anticoagulant? Int J Parasitol 38:1579-1588. 10.1016/j.ijpara.2008.05.002

Ghedin E, Wang S, Spiro D, Caler E, Zhao Q, Crabtree J, Allen JE, Delcher AL, Guiliano DB, Miranda-Saavedra D, Angiuoli SV, Creasy T, Amedeo P, Haas B, El-Sayed NM, Wortman JR, Feldblyum T, Tallon L, Schatz M, Shumway M, Koo H, Salzberg SL, Schobel S, Pertea M, Pop M, White O, Barton GJ, Carlow CK, Crawford MJ, Daub J, 
435

436

437

438

439

440

441

442

443

444

445

446

447

448

449

450

451

452

453

454

455

456

457

458

460

461

Dimmic MW, Estes CF, Foster JM, Ganatra M, Gregory WF, Johnson NM, Jin J, Komuniecki R, Korf I, Kumar S, Laney S, Li BW, Li W, Lindblom TH, Lustigman S, Ma D, Maina CV, Martin DM, McCarter JP, McReynolds L, Mitreva M, Nutman TB, Parkinson J, Peregrin-Alvarez JM, Poole C, Ren Q, Saunders L, Sluder AE, Smith K, Stanke M, Unnasch TR, Ware J, Wei AD, Weil G, Williams DJ, Zhang Y, Williams SA, Fraser-Liggett C, Slatko B, Blaxter ML, and Scott AL. 2007. Draft genome of the filarial nematode parasite Brugia malayi. Science 317:1756-1760. 10.1126/science.1145406

Guo Z, Gonzalez JF, Hernandez JN, McNeilly TN, Corripio-Miyar Y, Frew D, Morrison T, Yu P, and Li RW. 2016. Possible mechanisms of host resistance to Haemonchus contortus infection in sheep breeds native to the Canary Islands. Sci Rep 6:26200. $10.1038 /$ srep 26200

Haslam SM, Coles GC, Reason AJ, Morris HR, and Dell A. 1998. The novel core fucosylation of Haemonchus contortus $\mathrm{N}$-glycans is stage specific. Molecular and Biochemical Parasitology 93:143-147. http://dx.doi.org/10.1016/S0166-6851(98)00020-6

Hewitson JP, Grainger JR, and Maizels RM. 2009. Helminth immunoregulation: The role of parasite secreted proteins in modulating host immunity. Molecular and Biochemical Parasitology 167:1-11. http://dx.doi.org/10.1016/j.molbiopara.2009.04.008

Hoorens P, Rinaldi M, Mihi B, Dreesen L, Grit G, Meeusen E, Li RW, and Geldhof P. 2011. Galectin-11 induction in the gastrointestinal tract of cattle following nematode and protozoan infections. Parasite Immunology 33:669-678. 10.1111/j.13653024.2011.01336.x

Kemp JM, Robinson NA, Meeusen ENT, and Piedrafita DM. 2009. The relationship between the rapid rejection of Haemonchus contortus larvae with cells and mediators in abomasal tissues in immune sheep. International Journal for Parasitology 39:1589-1594. http://dx.doi.org/10.1016/j.ijpara.2009.05.015

Knox D. 2011. Proteases in blood-feeding nematodes and their potential as vaccine candidates. Adv Exp Med Biol 712. 
462 Liu LX, and Weller PF. 1992. Intravascular filarial parasites inhibit platelet aggregation. Role of 463 parasite-derived prostanoids. Journal of Clinical Investigation 89:1113-1120.

464 Maduzia LL, Yu E, and Zhang Y. 2011. Caenorhabditis elegans Galectins LEC-6 and LEC-10 465 Interact with Similar Glycoconjugates in the Intestine. Journal of Biological Chemistry $466 \quad 286: 4371-4381$.

467

468

469

470

471

472 473

474

475

476

477

478

479

480

481

482

483 484 485

486 487

Mavrot F, Hertzberg H, and Torgerson P. 2015. Effect of gastro-intestinal nematode infection on sheep performance: a systematic review and meta-analysis. Parasites \& Vectors 8:557. 10.1186/s13071-015-1164-Z

McLeod RS. 1995. Cost of major parasites to the Australian livestock industries. Int J Parasitol 25. 10.1016/0020-7519(95)00071-9

Meeusen ENT, and Balic A. 2000. Do Eosinophils have a Role in the Killing of Helminth Parasites? Parasitology Today 16:95-101. 10.1016/S0169-4758(99)01607-5

Meeusen ENT, Balic A, and Bowles V. 2005. Cells, cytokines and other molecules associated with rejection of gastrointestinal nematode parasites. Veterinary Immunology and Immunopathology 108:121-125. http://dx.doi.org/10.1016/j.vetimm.2005.07.002

Menon RP, Strom M, and Hughes RC. 2000. Interaction of a novel cysteine and histidine-rich cytoplasmic protein with galectin-3 in a carbohydrate-independent manner. FEBS Letters 470:227-231. 10.1016/S0014-5793(00)01310-7

Munn EA, Greenwood CA, and Coadwell WJ. 1987. Vaccination of young lambs by means of a protein fraction extracted from adult Haemonchus contortus. Parasitology 94 ( Pt 2):385397.

Newlands GFJ SP, Nisbet AJ, Redmond DL, Smith SK, Petitit D, Smith WD. 2006. Molecular characterization of a family of metalloendopeptidases from the intestinal brush border of Haemonchus contortus. Parasitology 133:357-368.

Newton SE, and Munn EA. 1999. The development of vaccines against gastrointestinal nematode parasites, particularly Haemonchus contortus. Parasitol Today 15:116-122. 
488 Nguyen VA, Carey LM, Giummarra L, Faou P, Cooke I, Howells DW, Tse T, Macaulay SL, Ma

489

490

491

492

493

494

495

496

497

498

499

500

501

502

503

504

505

506

507

508

509

510

511

512

513

H, Davis SM, Donnan GA, and Crewther SG. 2016. A Pathway Proteomic Profile of Ischemic Stroke Survivors Reveals Innate Immune Dysfunction in Association with Mild Symptoms of Depression - A Pilot Study. Frontiers in Neurology 7:85. 10.3389/fneur.2016.00085

Nikolaou S, and Gasser RB. 2006. Prospects for exploring molecular developmental processes in Haemonchus contortus. International Journal for Parasitology 36:859-868. http://dx.doi.org/10.1016/j.ijpara.2006.04.007

Nisbet AJ, Meeusen EN, González JF, and Piedrafita DM. 2016. Chapter Eight - Immunity to Haemonchus contortus and Vaccine Development. In: Robin BG, and Georg Von S-H, eds. Advances in Parasitology: Academic Press, 353-396.

O’Rourke D, Baban D, Demidova M, Mott R, and Hodgkin J. 2006. Genomic clusters, putative pathogen recognition molecules, and antimicrobial genes are induced by infection of $\mathrm{C}$. elegans with M. nematophilum. Genome Research 16:1005-1016. 10.1101/gr.50823006

Paz AH, R.; Elad-Sfadia, G.; Ballan, E.; Kloog, Y. 2001. Galectin-1 binds oncogenic H-Ras to mediate Rasmembrane anchorage and cell transformation. Oncogene 20:7486-7493.

Perkins DN, Pappin DJC, Creasy DM, and Cottrell JS. 1999. Probability-based protein identification by searching sequence databases using mass spectrometry data. ELECTROPHORESIS 20:3551-3567.

Preston S, Dunphy J, Beddoe T, Meeusen E, and Young A. 2015a. Evaluation of the role of galectins in parasite immunity. In: Stowell SR, and Cummings RD, eds. Galectins: Methods and Protocols. New York, NY: Springer New York, 371-395.

Preston SJM, Beddoe T, Walkden-Brown S, Meeusen E, and Piedrafita D. 2015b. Galectin-11: A novel host mediator targeting specific stages of the gastrointestinal nematode parasite, Haemonchus contortus. International Journal for Parasitology 45:791-796. http://dx.doi.org/10.1016/j.ijpara.2015.06.003 
514 Rappsilber J, Mann M, and Ishihama Y. 2007. Protocol for micro-purification, enrichment, pre-

515

516

517

518

519

520

521

522

523

524

525

526

527

528

529

530

531

532

533

534

535

536

537

538

539

fractionation and storage of peptides for proteomics using stage tips. Nat Protocols 2:1896-1906.

Robinson N, Pleasance J, Piedrafita D, and Meeusen EN. 2011. The kinetics of local cytokine and galectin expression after challenge infection with the gastrointestinal nematode, Haemonchus contortus. International Journal for Parasitology 41:487-493. 10.1016/j.ijpara.2010.11.006

Roeber F, Jex AR, and Gasser RB. 2013. Impact of gastrointestinal parasitic nematodes of sheep, and the role of advanced molecular tools for exploring epidemiology and drug resistance - an Australian perspective. Parasites \& Vectors 6:153-153. 10.1186/1756-3305-6-153

Rydz N, Swystun LL, Notley C, Paterson AD, Riches JJ, Sponagle K, Boonyawat B, Montgomery RR, James PD, and Lillicrap D. 2013. The C-type lectin receptor CLEC4M binds, internalizes, and clears von Willebrand factor and contributes to the variation in plasma von Willebrand factor levels. Blood 121:5228-5237. 10.1182/blood-2012-10457507

Sakthivel D, Littler D, Shahine A, Troy S, Johnson M, Rossjohn J, Piedrafita D, and Beddoe T. 2015. Cloning, expression, purification and crystallographic studies of galectin-11 from domestic sheep (Ovis aries). Acta Crystallographica Section F 71:993-997. doi:10.1107/S2053230X15010195

Schwarz EM, Korhonen PK, Campbell BE, Young ND, Jex AR, and Jabbar A. 2013. The genome and developmental transcriptome of the strongylid nematode Haemonchus contortus. Genome Biol 14. 10.1186/gb-2013-14-8-r89

Searle BC. 2010. Scaffold: A bioinformatic tool for validating MS/MS-based proteomic studies. PROTEOMICS 10:1265-1269. 10.1002/pmic.200900437

Shannon P, Markiel A, Ozier O, Baliga NS, Wang JT, Ramage D, Amin N, Schwikowski B, and Ideker T. 2003. Cytoscape: A Software Environment for Integrated Models of 
Biomolecular Interaction Networks. Genome Research 13:2498-2504.

542 Smith SK, Pettit D, Newlands GF, Redmond DL, Skuce PJ, Knox DP, and Smith WD. 1999. Further immunization and biochemical studies with a protective antigen complex from the microvillar membrane of the intestine of Haemonchus contortus. Parasite Immunol 21:187-199.

546

547

548

549

550

551

552

553

554

555

556

557

558

559

560

561

562

563

Smith WD, Smith SK, Pettit D, Newlands GF, and Skuce PJ. 2000. Relative protective properties of three membrane glycoprotein fractions from Haemonchus contortus. Parasite Immunol 22:63-71.

Strube C, Haake C, Sager H, Schorderet Weber S, Kaminsky R, Buschbaum S, Joekel D, Schicht S, Kremmer E, Korrell J, Schnieder T, and von Samson-Himmelstjerna G. 2015. Vaccination with recombinant paramyosin against the bovine lungworm Dictyocaulus viviparus considerably reduces worm burden and larvae shedding. Parasites \& Vectors 8:119. 10.1186/s13071-015-0733-5

Talaga ML, Fan N, Fueri AL, Brown RK, Bandyopadhyay P, and Dam TK. 2016. Multitasking Human Lectin Galectin-3 Interacts with Sulfated Glycosaminoglycans and Chondroitin Sulfate Proteoglycans. Biochemistry 55:4541-4551. 10.1021/acs.biochem.6b00504

Tellam RL, Kemp D, Riding G, Briscoe S, Smith D, Sharp P, Irving D, and Willadsen P. 2002. Reduced oviposition of Boophilus microplus feeding on sheep vaccinated with vitellin. Veterinary Parasitology 103:141-156. http://dx.doi.org/10.1016/S0304-4017(01)00573-8

Vasta GR, Feng C, Gonzalez-Montalban N, Mancini J, Yang L, Abernathy K, Frost G, and Palm C. 2017. Functions of galectins as 'self/non-self'-recognition and effector factors. Pathog Dis 75. 10.1093/femspd/ftx046

Veglia F. 1915. The anatomy and life history of the Haemonchus contortus (Rud). Report on Veterinary Research Department of Agriculture, Union of South Africa 3:349-500.

Wang J, and Kim SK. 2003. Global analysis of dauer gene expression in Caenorhabditis elegans. Development 130:1621. 
567 Whittaker CA, and Hynes RO. 2002. Distribution and evolution of von willebrand/integrin A 568 domains: widely dispersed domains with roles in cell adhesion and elsewhere. Molecular Biology of the Cell 13:3369-3387.

570 Wohner N, Kovács A, Machovich R, and Kolev K. 2012. Modulation of the von Willebrand

571

572

573

574

575

576

577

578

579

580

581

582

583

584

585 factor-dependent platelet adhesion through alternative proteolytic pathways. Thrombosis Research 129:e41-e46. 10.1016/j.thromres.2011.11.021

Yatsuda AP, Krijgsveld J, Cornelissen AW, Heck AJ, and de Vries E. 2003. Comprehensive analysis of the secreted proteins of the parasite Haemonchus contortus reveals extensive sequence variation and differential immune recognition. $J$ Biol Chem 278:16941-16951. 10.1074/jbc.M212453200

Young AR, Barcham GJ, Kemp JM, Dunphy JL, Nash A, and Meeusen EN. 2009. Functional characterization of an eosinophil-specific galectin, ovine galectin-14. Glycoconjugate Journal 26:423-432. 10.1007/s10719-008-9190-0

Young AR, Barcham GJ, McWilliam HE, Piedrafita DM, and Meeusen EN. 2012. Galectin secretion and binding to adult Fasciola hepatica during chronic liver fluke infection of sheep. Vet Immunol Immunopathol 145:362-367. 10.1016/j.vetimm.2011.12.010 


\section{Table $\mathbf{1}$ (on next page)}

Identification by mass spectroscopy of larval and adult Haemonchus contortus proteins eluted from LGALS-11 and LGALS-14 columns 


\begin{tabular}{|c|c|c|c|c|c|c|c|c|c|c|c|c|c|c|}
\hline \multirow{2}{*}{ Accession code } & \multirow{2}{*}{ Gene description } & \multirow{2}{*}{$\mathrm{CV}$} & \multirow{2}{*}{ PSMs } & \multirow{2}{*}{$\mathbf{U P}$} & \multirow[t]{2}{*}{$\begin{array}{l}\text { Mascot } \\
\text { Score }\end{array}$} & \multicolumn{4}{|c|}{ Groups } & \multirow[t]{2}{*}{$\begin{array}{l}\text { Log- } \\
\text { odds }\end{array}$} & \multirow[t]{2}{*}{ NSAF } & \multirow{2}{*}{$\begin{array}{l}\text { MW } \\
\text { (kDa) }\end{array}$} & \multirow{2}{*}{$\begin{array}{l}\text { Signal } \\
\text { peptid } \\
\text { e }\end{array}$} & \multirow{2}{*}{ 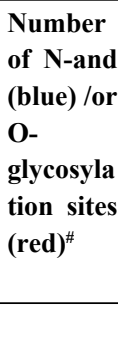 } \\
\hline & & & & & & 1 & 2 & 3 & 4 & & & & & \\
\hline \multicolumn{15}{|c|}{ Metabolic process } \\
\hline W6NE18 & Peptidase S28 GN=HCOI_01497800 & 45.21 & 634 & 20 & 7058 & No & Yes & Yes & Yes & 145.70 & 0.071 & 67.1 & No & $1 / 5$ \\
\hline W6NFG0 & $\begin{array}{l}\text { Alpha beta hydrolase fold-1 } \\
\text { GN=HCOI_00457700 }\end{array}$ & 58.65 & 504 & 16 & 6681 & No & Yes & Yes & Yes & 128.68 & 0.129 & 36.6 & Yes & $1 / 0$ \\
\hline W6NFT9 & Peptidase S28 GN=HCOI_01562400 & 23.27 & 222 & 18 & 3151 & No & Yes & No & Yes & 11.26 & 0.0062 & 128.6 & Yes & $7 / 35$ \\
\hline W6NJ96 & Carboxyl transferase GN=HCOI_00766200 & 23.39 & 123 & 10 & 1146 & No & Yes & No & Yes & 16.01 & 0.0103 & 56.1 & No & $0 / 7$ \\
\hline W6NLA8 & $\begin{array}{l}\text { Glutamate phenylalanine leucine valine } \\
\text { dehydrogenase GN=HCOI_01838800 }\end{array}$ & 42.50 & 102 & 10 & 957 & No & Yes & No & Yes & 20.61 & 0.020 & 26.8 & No & $0 / 0$ \\
\hline W6NG90 & Peptidase S28 GN=HCOI_01624000 & 4.88 & 101 & 3 & 1218 & No & Yes & No & Yes & 29.6 & 0.003 & 117.0 & Yes & $4 / 7$ \\
\hline W6NC58 & Aldo keto reductase GN=HCOI_00043700 & 39.64 & 83 & 10 & 789 & No & Yes & No & Yes & -0.18 & 0.009 & 38.0 & No & $3 / 6$ \\
\hline W6NAV8 & Aldo keto reductase GN=HCOI_00043500 & 27.22 & 46 & 6 & 477 & No & Yes & No & Yes & -0.18 & 0.0028 & 40.0 & No & $2 / 4$ \\
\hline W6NU27 & Carboxyl transferase GN=HCOI_00766300 & 25.83 & 67 & 6 & 909 & No & Yes & No & Yes & 4.35 & 0.0023 & 42.2 & No & $1 / 0$ \\
\hline W6NKM1 & $\begin{array}{l}\text { Succinate dehydrogenase iron-sulfur subunit, } \\
\text { GN=HCOI_01735500 }\end{array}$ & 32.61 & 64 & 8 & 521 & No & Yes & No & Yes & 34.83 & 0.0067 & 31.6 & No & $1 / 10$ \\
\hline W6NF70 & Deoxynucleoside kinase GN=HCOI_01673500 & 35.42 & 42 & 6 & 242 & No & No & No & Yes & -0.18 & 0.0012 & 34.8 & No & $0 / 0$ \\
\hline U6NNG6 & Ribosomal protein L7 L12 GN=HCOI_00340500 & 11.41 & 30 & 1 & 783 & No & Yes & No & Yes & -0.18 & 0.013 & 19.5 & No & $1 / 3$ \\
\hline W6NA79 & $\begin{array}{l}\text { Zinc metallopeptidase M13 } \\
\text { GN=HCOI_01030800 }\end{array}$ & 37.90 & 28 & 3 & 330 & No & No & No & Yes & 4.35 & 0.0067 & 14.6 & No & $0 / 2$ \\
\hline W6ND82 & $\begin{array}{l}\text { von Willebrand factor domain containing protein } \\
\text { GN=HCOI_01354500 }\end{array}$ & 13.82 & 26 & 3 & 371 & No & No & No & Yes & 16.01 & 0.0077 & 27.5 & Yes & $2 / 0$ \\
\hline W6NMI7 & Proteinase inhibitor I33 GN=HCOI_02015200 & 18.58 & 22 & 5 & 162 & No & No & No & Yes & -0.18 & 0.0020 & 25.1 & Yes & $0 / 7$ \\
\hline W6NKG5 & Ribosomal protein L15 GN=HCOI_01717500 & 5.88 & 4 & 1 & 26 & No & No & No & Yes & 5.67 & 0.0002 & 24.3 & No & $1 / 10$ \\
\hline W6NEW9 & Amidinotransferase GN=HCOI_01556200 & 23.35 & 24 & 4 & 109 & No & Yes & No & No & -0.18 & 0.0014 & 29.2 & No & $0 / 0$ \\
\hline W6NI22 & Adenylosuccinate lysase GN=HCOI_00436500 & 6.41 & 14 & 3 & 141 & No & Yes & No & No & 12.23 & 0.0005 & 76.9 & No & $1 / 4$ \\
\hline
\end{tabular}




\begin{tabular}{|c|c|c|c|c|c|c|c|c|c|c|c|c|c|c|}
\hline W6NF84 & $\begin{array}{l}\text { Short-chain dehydrogenase reductase } \\
\text { GN=HCOI_01467500 }\end{array}$ & 3.07 & 11 & 1 & 137 & No & Yes & No & Yes & 1.71 & 0.0003 & 27.5 & No & $0 / 0$ \\
\hline W6ND43 & $\begin{array}{l}\text { Acetyltransferase component of pyruvate } \\
\text { dehydrogenase complex GN=HCOI_00576100 }\end{array}$ & 1.22 & 8 & 1 & 51 & No & Yes & No & No & 1.68 & 0.0001 & 78.3 & No & $1 / 40$ \\
\hline \multicolumn{15}{|c|}{ Regulation of biological processes } \\
\hline W6NC73 & ATPase GN=HCOI_02138200 & 22.64 & 23 & 2 & 418 & No & Yes & No & Yes & -0.18 & 0.004 & 17.8 & No & $1 / 0$ \\
\hline W6NJ12 & $\begin{array}{l}\text { Filament domain containing protein } \\
\text { GN=HCOI_02013700 }\end{array}$ & 14.09 & 20 & 3 & 291 & No & Yes & No & Yes & -0.18 & 0.0028 & 34.2 & No & $0 / 4$ \\
\hline W6NM02 & Fumarate lyase GN=HCOI_01914600 & 4.73 & 8 & 1 & 62 & No & Yes & No & No & 4.61 & 0.0003 & 29.7 & No & $1 / 12$ \\
\hline W6NGK5 & CRE-DHS-15 protein GN=HCOI_00341400 & 29.31 & 6 & 1 & 210 & No & No & No & Yes & -0.18 & 0.0031 & 6.1 & No & $0 / 1$ \\
\hline W6NI80 & Acyl-CoA-binding protein GN=HCOI_01539100 & 20.69 & 6 & 1 & 205 & No & Yes & No & Yes & 6.69 & 0.0018 & 9.5 & No & $0 / 1$ \\
\hline W6NCC1 & NIPSNAP GN=HCOI_01963300 & 7.63 & 6 & 1 & 75 & No & Yes & No & No & -0.18 & 0.0013 & 26.5 & No & $0 / 6$ \\
\hline W6NWY9 & $\begin{array}{l}\text { Porin domain containing protein } \\
\text { GN=HCOI_01573900 }\end{array}$ & 43.97 & 82 & 9 & 1149 & No & Yes & No & Yes & 4.35 & 0.011 & 30.2 & No & $3 / 0$ \\
\hline W6NAW4 & $\begin{array}{l}\text { FG-GAP and Integrin alpha-2/Integrin alpha } \\
\text { chain GN=HCOI_01903100 }\end{array}$ & 5.90 & 33 & 5 & 340 & No & Yes & No & Yes & -0.18 & 0.0028 & 133.9 & Yes & $5 / 18$ \\
\hline W6NAL4 & Heat shock protein 70 GN=HCOI_00589700 & 7.24 & 9 & 1 & 82 & No & Yes & No & No & 7.23 & 0.0002 & 72.4 & No & $3 / 7$ \\
\hline \multicolumn{15}{|l|}{ Transport } \\
\hline W6NVQ1 & $\begin{array}{l}\text { Lipid transport protein and Vitellinogen and von } \\
\text { Willebrand factor domain GN=HCOI_01683400 }\end{array}$ & 23.18 & 209 & 24 & 1465 & No & Yes & No & Yes & 9.62 & 0.0039 & 156.0 & No & $0 / 11$ \\
\hline W6N9I2 & Lipid transport protein GN=HCOI_00072100 & 35.97 & 139 & 13 & 1313 & No & Yes & No & Yes & 51.51 & 0.0136 & 56.8 & Yes & $0 / 2$ \\
\hline W6NQZ5 & $\begin{array}{l}\text { Mitochondrial substrate solute carrier } \\
\text { GN=HCOI_01092000 }\end{array}$ & 23.10 & 53 & 8 & 334 & No & No & No & Yes & 6.2 & 0.0033 & 36.3 & No & $0 / 3$ \\
\hline \multicolumn{15}{|c|}{ Cytoskeleton } \\
\hline W6NAH7 & $\begin{array}{l}\text { Nematode cuticle collagen and Collagen triple } \\
\text { helix repeat GN=HCOI_00810700 }\end{array}$ & 5.60 & 85 & 2 & 1399 & No & Yes & No & Yes & 4.35 & 0.0117 & 32.8 & No & $0 / 15$ \\
\hline W6NHH0 & Annexin GN=HCOI_01003500 & 14.01 & 22 & 3 & 135 & No & Yes & No & No & -0.18 & 0.0008 & 29.4 & No & $0 / 1$ \\
\hline W6NE41 & Myosin tail GN=HCOI_01216000 & 3.99 & 17 & 3 & 59 & No & Yes & No & No & 13.42 & 0.0008 & 54.7 & No & $0 / 15$ \\
\hline W6NF56 & Myosin tail GN=HCOI_01461300 & 34.48 & 51 & 8 & 675 & No & Yes & No & Yes & 6.2 & 0.0040 & 36.5 & No & $0 / 14$ \\
\hline
\end{tabular}




\begin{tabular}{|c|c|c|c|c|c|c|c|c|c|c|c|c|c|c|}
\hline \multicolumn{15}{|c|}{ Immunomodulatory } \\
\hline W6NGA7 & SCP extracellular domain GN=HCOI_01577700 & 14.95 & 4 & 2 & 59 & No & Yes & No & Yes & -0.18 & 0.0011 & 22.2 & No & $1 / 1$ \\
\hline \multicolumn{15}{|l|}{ Unknown } \\
\hline W6NAN9 & CBN-MLC-3 protein GN=HCOI_01274700 & 49.67 & 63 & 7 & 465 & No & Yes & No & Yes & 2.32 & 0.0086 & 17.0 & No & $0 / 2$ \\
\hline W6NX42 & Uncharacterized protein GN=HCOI_01051700 & 25.56 & 38 & 3 & 607 & No & No & No & Yes & 19.09 & 0.0066 & 25.5 & No & $4 / 40$ \\
\hline W6NFI4 & Protein C15F1.2 GN=HCOI_01126300 & 34.87 & 20 & 4 & 97 & No & Yes & No & Yes & -0.18 & 0.0022 & 27.1 & Yes & $0 / 13$ \\
\hline W6NB42 & $\begin{array}{l}\text { Protein C23H5.8, isoform-c } \\
\text { GN=HCOI_00648100 }\end{array}$ & 14.43 & 16 & 2 & 170 & No & Yes & No & Yes & 10.80 & 0.0025 & 22.5 & Yes & $1 / 1$ \\
\hline W6NPK3 & Uncharacterized protein GN=HCOI_00260500 & 5.20 & 10 & 1 & 45 & No & No & No & Yes & -0.18 & 0.0001 & 22.6 & Yes & $3 / 11$ \\
\hline W6NUX4 & Uncharacterized protein GN=HCOI_01608400 & 4.04 & 12 & 1 & 43 & No & Yes & No & Yes & 4.04 & 0.0002 & 21.8 & Yes & $0 / 6$ \\
\hline
\end{tabular}

\section{Abbreviations:}

$3 \mathrm{GN}=$ Gene name; $\mathrm{CV}=$ Coverage; PSMs = Peptide spectrum matches; $\mathrm{UP}=$ Unique peptides;

4 Log-odds $0=50 \%$ chance, Positive values $=$ More than $50 \%$, Negative values $=$ Less than $50 \%$

5 Groups:

61 = LGALS-11 bound protein from L4 larval stage of $H$. contortus

72 = LGALS-11 bound protein from adult stage of $H$. contortus

$83=$ LGALS-14 bound protein from L4 larval stage of $H$. contortus

94 = LGALS-14 bound protein from adult stage of $H$. contortus

10 \#Predicated glycosylation sites as determined in materials and methods.

$11 \mathrm{NSAF}=$ Normalized Spectral Abundance Factor 


\section{Figure 1}

LGALS-11 and LGALS-14 interactome

(A) Protein profiling of larval and adult stages of Haemonchus contortus. (M)

Molecular weight markers; (Lane $1 \& 2$ ) lysates prepared from L4 stage; (Lane 3) lysates prepared from adult stage. (B) Protein profile of adult stage parasite bound to LGALS-

11 and LGALS-14 and (C) larval stage parasite bound to LGALS-11 and LGALS-14. M) Molecular weight markers; (Lane 1) Total parasite lysate, (Lane $2 \& 3$ ) Unbound protein fractions of LGALS-11 and LGALS-14 column, (Lane $4 \& 5$ ) Column wash of LGALS-11 and LGALS-14 column and (Lane $6 \& 7$ ) eluted protein of LGALS-11 and LGALS-14 column.

A

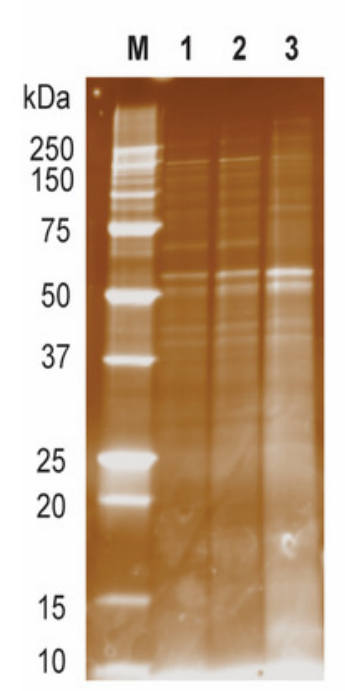

B

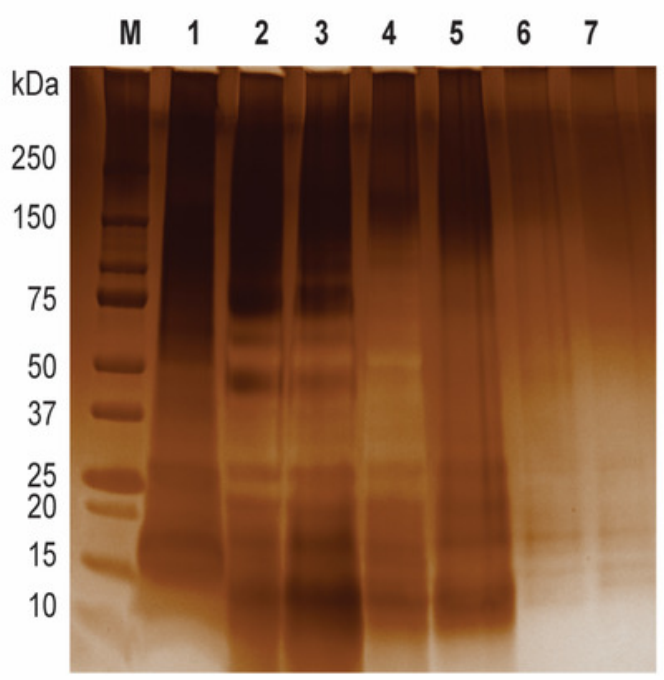

C

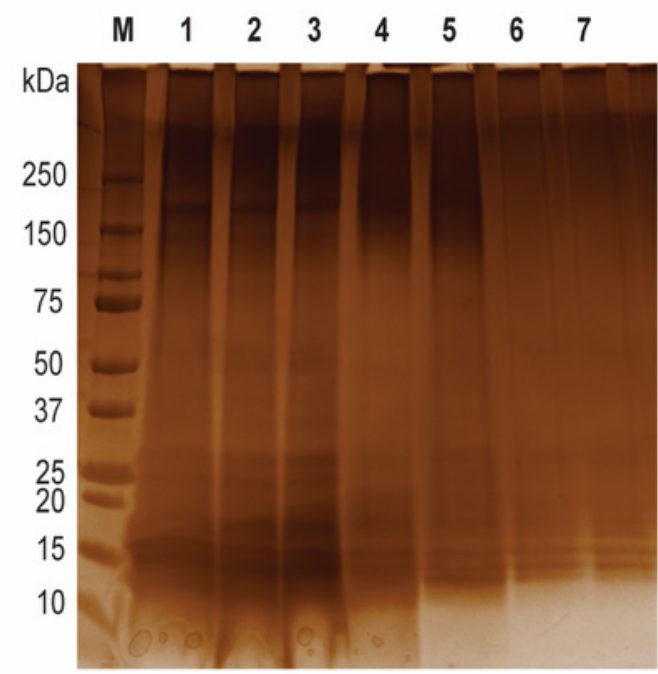


Figure 2

Venn diagram of parasite proteins bound by host galectins.

Venn diagram showing the distribution of proteins of the larval $(A)$ and adult $(B)$ stages of Haemonchus contortus. In larval and adult stages, 0 and 26 proteins were bound by both the galectins respectively.

A

\section{Larval Stage}

LGALS-11

LGALS-14

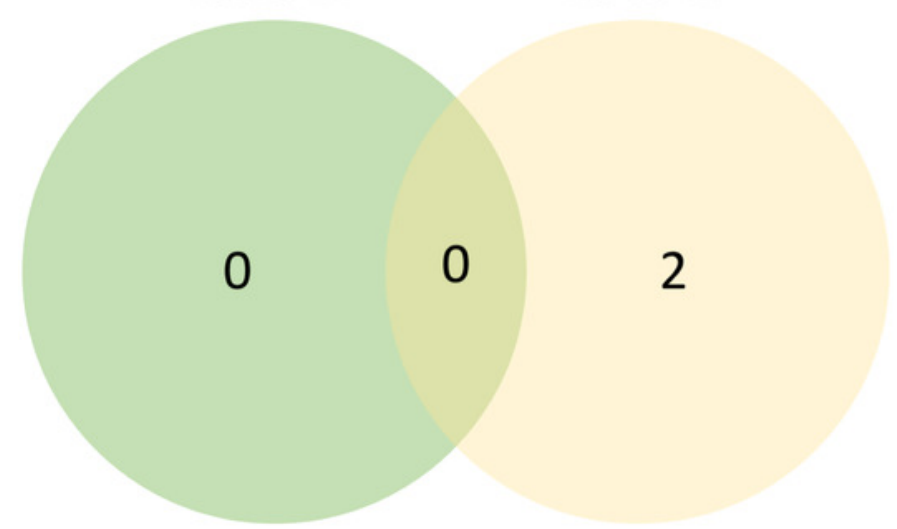

B

\section{Adult Stage}

LGALS-11

LGALS-14

8

26

9 
Figure 3

Categorisation of proteins in the adult stage of Haemonchus contortus that interacted with host galectins.

The profiles were categorised based on biological process of LGALS-11-bound proteins (A) and LGALS-14 bound-proteins (B) and cellular location of LGALS-11-bound proteins (C) and LGALS-14-bound proteins (D).

\section{Biological Process}

A

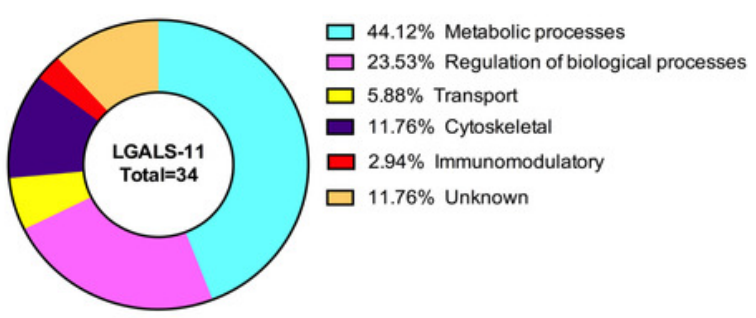

B

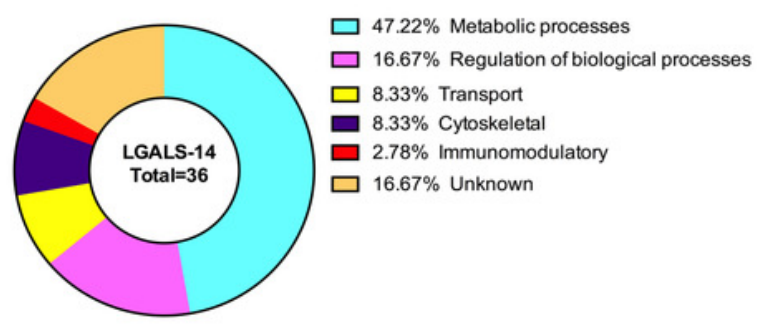

\section{Cellular componnent}

C

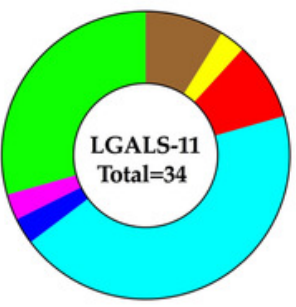

D

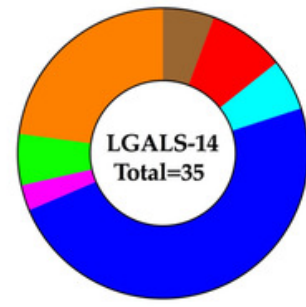

Cytoplasm $(9.09 \%)$

Endosome $(3.64 \%)$

Extracellular (5.45\%)

Membrane; Mitochondrion (10.91\%)

Membrane $(45.45 \%)$

Nucleus $(9.09 \%)$

Ribosome $(1.82 \%)$

Cytoplasm $(9.09 \%)$

Endosome $(3.64 \%)$

Extracellular (5.45\%)

Membrane; Mitochondrion (10.91\%)

Membrane $(\mathbf{4 5 . 4 5 \% )}$

Nucleus $(9.09 \%)$

Ribosome $(1.82 \%)$ 
Figure 4 (on next page)

Protein-protein interaction network of adult stage of Haemonchus contortus with host galectins.

Protein interactions was determined using the software (SAINT) (Choi et al. 2011) and resulting interaction network was visualised using the Cytoscape v3.4.0. 


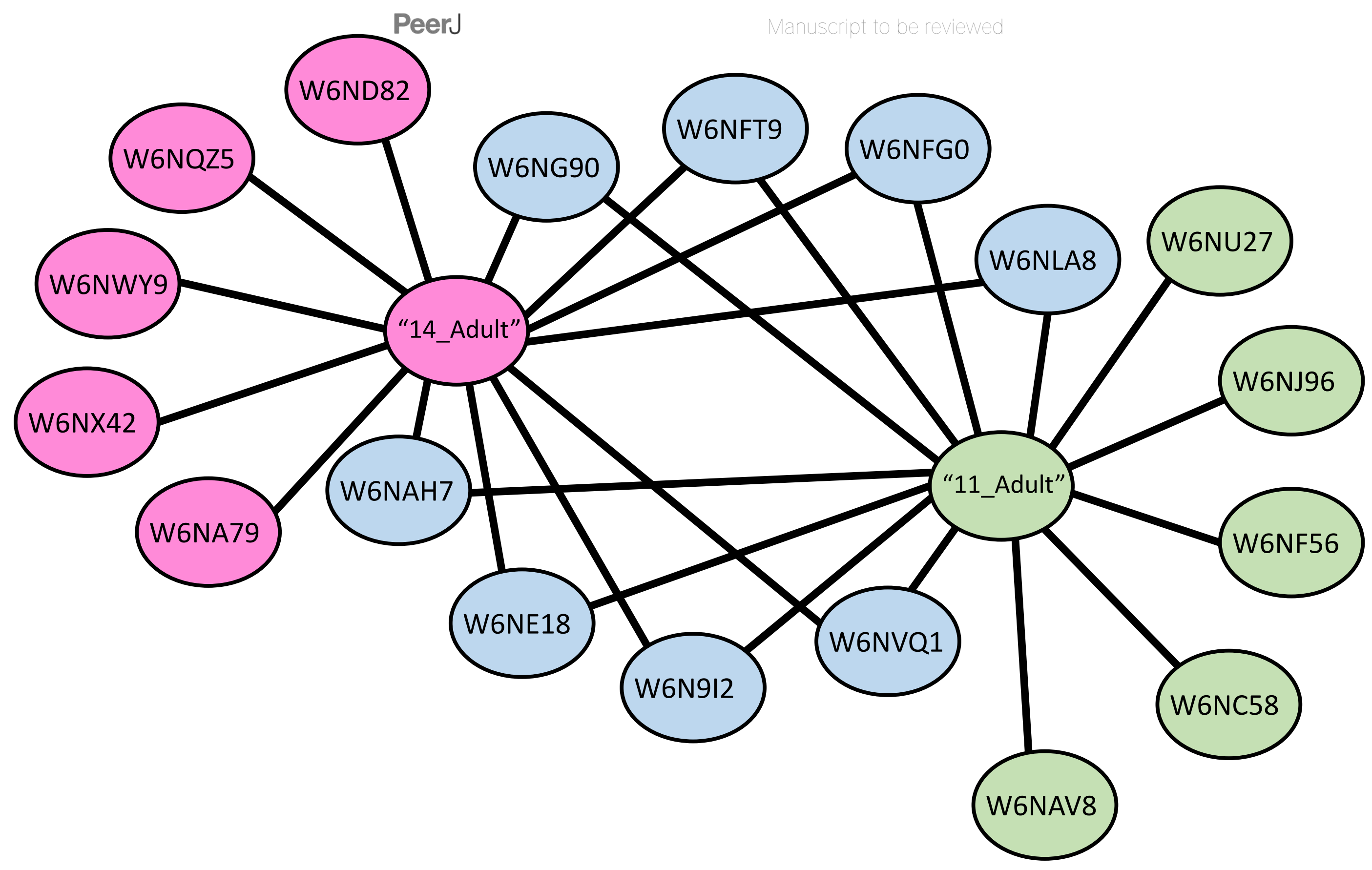

